\title{
Matemática no Ensino Médio: ensino para a formação de conceitos e desenvolvimento dos alunos ${ }^{*}$
}

\author{
Mathematics in High School: teaching for the \\ formation of concepts and students' development
}

\section{Matemática en la Enseñanza Media: enseñanza para la formación de conceptos y desarrollo de los alumnos}

\author{
Thalitta Fernandes de Carvalho Peres** \\ Raquel Aparecida Marra da Madeira Freitas ${ }^{* * *}$
}

\begin{abstract}
Resumo: A pesquisa fundamentada na teoria de V. V. Davydov consistiu-se em um experimento didático formativo realizado no Ensino Médio de uma escola pública, com o objetivo de identificar as contribuições e os desafios ao ensino de geometria espacial organizado a partir dos princípios desta teoria. A coleta de dados ocorreu por meio de entrevistas, observações, instrumentos de avaliação da aprendizagem dos alunos. Os resultados mostram o ensino desenvolvimental como uma alternativa para a superação dos tipos de ensino de Matemática que não privilegiam o desenvolvimento do aluno. Mostram também dificuldades e contradições relacionadas a fatores socioculturais e históricos envolvendo os alunos e o processo de escolarização. Conclui-se que o ensino desenvolvimental é uma proposta que exige mais do professor e é promissora para a aquisição de novas formações mentais em Matemática pelos alunos.
\end{abstract}

Palavras-chave: Ensino de Matemática. Ensino desenvolvimental. Didática.

\begin{abstract}
The study, based on V. V. Davydoy's theory, consisted of formative didactic experiment carried out at the high school level in a public school, aiming to identify the contributions and challenges to the teaching of spatial geometry, organized according to this theory. Data collection occurred through interviews, observations, and students' learning evaluation instruments. Results revealed the developmental teaching as an
\end{abstract}

\footnotetext{
* Este artigo descreve parte da Dissertação de Mestrado intitulada Volume de Sólidos Geométricos - um Experimento de Ensino baseado na Teoria de V. V. Davydov, apresentada ao Programa de Pós-Graduação em Educação da Pontifícia Universidade Católica de Goiás (PUC Goiás), sob a orientação da Prof ${ }^{a}$ Dra. Raquel A. Marra da Madeira Freitas, com financiamento da FAPEG - Fundação de Amparo à Pesquisa do Estado de Goiás.

** Professora da Universidade Estadual de Goiás - UEG - Unidade Universitária de Iporá. E-mail: $<$ thalitta@hotmail.com>

*** Professora do Programa de Pós-Graduação da Pontifícia Universidade Católica de Goiás - PUC Goiás. E-mail: <raquelmarram@gmail.com>
} 
alternative to overcome types of Mathematics teaching which do not favor students' development. At the same time, they pointed to difficulties and contradictions related to socio-cultural and historical factors involving students and the schooling process. It was concluded that the developmental teaching is a demanding proposal for the teaching, but promising regarding the acquisition of new mental awareness of Mathematics by students.

Keywords: Teaching of Mathematics. Developmental teaching. Didactics.

Resumen: La investigación fundamentada en la teoría de V. V. Davydov se estribó en un experimento didáctico formativo llevado a cabo en la Secundaria de una escuela pública, con objetivo de identificar las contribuciones y los desafíos a la enseñanza de geometría espacial organizada a partir de los principios de esta teoría. La recogida de datos se dio por medio de entrevistas, observaciones, instrumentos de evaluación del aprendizaje de los alumnos. Los resultados muestran la enseñanza que conduce al desarrollo como una alternativa a la superación de los tipos de enseñanza de Matemática que no privilegian el desarrollo del alumno. Muestran, además, dificultades y contradicciones relacionadas a factores socioculturales e históricos que involucran a los alumnos y el proceso de escolarización. Se concluye que la enseñanza que conduce al desarrollo es una propuesta que exige más del profesor y es prometedora en cuanto a la adquisición de nuevas formaciones mentales en Matemática por parte de los alumnos.

Palabras clave: Enseñanza de Matemática. Enseñanza que conduce al desarrollo. Didáctica.

\section{Introdução}

Os baixos índices obtidos em Matemática por alunos em avaliações como Programa Internacional de Avaliação de Alunos (PISA) e Exame Nacional do Ensino Médio (ENEM), amplamente conhecidos no meio educacional, representam forte indício da necessidade de mudanças no seu ensino.

Sabe-se que entre os problemas a serem superados estão também fatores ligados à formação e à prática dos professores. Pesquisas e estudos recorrentes sobre o tema mostram a necessidade de formação com sólida base teórica e científica, especificamente em Matemática, associada a uma sólida base pedagógica (FIORENTINI et al., 2002; FIORENTINI, 2005, 2008).

Particularmente em geometria, persistem entre professores dificuldades para ensinar (MANRIQUE, 2003). Os professores têm dificuldade para ensinar, em geometria, as figuras tridimensionais em materiais bidimensionais. Pesquisadores como Van Hiele (1986), Duval (1988), Muller (1994), Fainguelernt (1999) e Parsysz (2001) defendem a importância da visualização no ensino da geometria para fazer avançar a aprendizagem dos alunos, pois a visualização possibilita aos alunos perceberem, no plano material, os elementos de um sólido geométrico. Por exemplo, relacionar altura, apótema e aresta de uma pirâmide. 
O ensino de geometria permanece sem muitas alterações também por ser este um ramo relegado a segundo plano, considerado como menos importante se comparado ao ensino de outras partes da Matemática (PAVANELLO, 1993; LORENZATO, 1995; PEREIRA, 2001; VASCONCELLOS, 2008). O resultado, como mostram Almouloud e Mello (2000), é o baixo desempenho dos alunos em avaliações da aprendizagem de Matemática, tornando-se ainda mais baixo quando se trata de geometria.

Esse contexto respalda a necessidade de estudos e análises que contribuam para a melhoria do ensino de geometria. Pondo-se neste movimento de busca, a presente pesquisa enfoca a organização do ensino de geometria espacial em conexão com a atividade de aprendizagem dos alunos.

De acordo com os princípios da teoria histórico-cultural formulada por Lev S. Vygotsky, há uma forte relação entre ensino, aprendizagem e desenvolvimento do pensamento dos alunos, sendo que o ensino tem o papel primordial de impulsionar o desenvolvimento. Entre os seguidores de Vygotsky, Vasili V. Davydov, pesquisador russo, formulou a teoria do ensino desenvolvimental, como uma referência teórica e um método de ensino. A partir de uma base geral fornecida por esta teoria, cabe às áreas de ensino das ciências realizar estudos e investigações em busca de contribuições para a constituição de formas de organização do ensino. Nessa perspectiva, a pesquisa aqui descrita buscou contribuir especificamente para o ensino de geometria espacial.

Pesquisadores em outros países (LOMPSCHER, 1999; HEDEGAARD, 2002), realizaram estudos e pesquisas fundamentadas na teoria do ensino desenvolvimental, descrevendo suas contribuições para o ensino de um conteúdo específico em distintos níveis do sistema escolar. No Brasil, são recentes os estudos e pesquisas com fundamentação na teoria de Davydov. Libâneo (2004) e Libâneo e Freitas (2007) descrevem o desenvolvimento desta teoria, apontando suas contribuições para a didática e didáticas das disciplinas.

Em Educação Matemática, Cedro (2004, 2008), Cedro e Moura (2007) Soares (2007) e Rosa (2009) desenvolveram pesquisas que trataram especificamente da organização do ensino de conteúdos de Matemática, abordando a atividade do professor e a influência de mudanças no ensino sobre processo de aprender dos alunos.

Com a mesma fundamentação, mas com foco na atividade coletiva, Moretti e Moura (2011) mostraram, em um processo de formação continuada de professores, mudanças no movimento das ações de ensino dos professores quando estes reorganizam coletivamente situações para desencadear a aprendizagem. 
As pesquisas mencionadas mostram a relação entre forma de organização do ensino e mudanças no processo de aprendizagem dos alunos. No entanto, não se localizou, até a realização desta pesquisa, nenhum trabalho com este enfoque abordando o ensino de geometria.

Nesta pesquisa, partiu-se da seguinte questão: que possibilidades e que desafios se apresentam para a realização do ensino de geometria espacial fundamentado na proposta de V. V. Davydov? O objetivo geral foi identificar, por meio de experimento didático formativo, as contribuições e os desafios ao ensino de geometria espacial organizado a partir dos princípios desta teoria, no contexto de uma escola pública estadual, em uma cidade do estado de Goiás.

Este artigo apresenta alguns resultados. Inicia-se abordando premissas da teoria histórico-cultural, em seguida, são descritos os elementos essenciais da proposta de organização do ensino formulada por Davydov, apresentando na sequência o experimento didático formativo para ensino do conceito de volume de prima, pirâmide, cilindro e cone. Por fim, apresentam-se algumas considerações acerca dos principais resultados da pesquisa.

\section{Ensino para a formação de conceitos e desenvolvimento dos alunos}

Vygotsky (1992, 1998, 2000, 2007) explicou o desenvolvimento psicológico humano como um processo decorrente da atividade humana histórica, mediante a apropriação da cultura e a comunicação entre as pessoas. Para ele, a mente humana se constitui e se desenvolve, sobretudo, sob a influência das relações sociais e culturais, em contextos históricos. $\mathrm{Na}$ cultura historicamente produzida, encontram-se as formas de relações sociais, os conhecimentos, as formas e métodos de pensar, conhecer, agir, que vão sendo compartilhadas e apropriadas de uma geração a outra. A aquisição desses conteúdos da cultura contribui para a formação de novas funções mentais. Sob essas premissas, o ensino escolar apresenta grande relevância, enquanto forma sistematizada de compartilhamento e transmissão de conteúdos culturais, científicos, éticos, políticos, estéticos etc. (LIBÂNEO; FREITAS, 2007).

Um dos conceitos mais conhecidos de Vygotsky é o de zona de desenvolvimento proximal (ZDP), em que ele associa a psicologia geral sobre o desenvolvimento da criança a uma visão pedagógica do ensino. A ZDP diz respeito à possibilidade do indivíduo para conhecer e agir sobre a realidade, mas com a ajuda de alguém mais experiente como pais, professores, colegas, outras pessoas (HEDEGAARD, 2002).

Vygotsky sintetiza o conceito de zona de desenvolvimento proximal da seguinte maneira: "O nível de desenvolvimento real caracteriza o desenvolvimento 
mental retrospectivamente, enquanto a zona de desenvolvimento proximal caracteriza o desenvolvimento mental prospectivamente" (VYGOTSKY, 2007, p. 98).

Por sua grande relevância pedagógica e didática, a zona de desenvolvimento proximal deve ser considerada no ensino, particularmente na formação de conceitos. Vygotsky (1992) descreve os conceitos como científicos e espontâneos (ou cotidianos). Os científicos são os oriundos da investigação científica, sistematizada, disponibilizados na escola de forma organizada, intencional. Os conceitos espontâneos ou cotidianos decorrem dos conhecimentos do dia-a-dia e são disponibilizados espontaneamente no cotidiano de vida. Ambos influenciam no desenvolvimento humano, porém, a aprendizagem dos conceitos científicos tem papel preponderante porque exige elevado grau de sistematização e reflexão, requerendo o exame consciente e intencional dos objetos, o trabalho mental de análise, síntese e abstração (VYGOTSKY, 1992). Uma vez abstraído, um conceito torna-se um elemento básico do pensamento. Vygotsky (2000, p. 226) explica: "O conceito surge quando uma série de atributos abstraídos torna a sintetizar-se, e quando a síntese abstrata assim obtida se torna forma basilar de pensamento com o qual a criança percebe e toma conhecimento da realidade que a cerca."

Forma superior de atividade mental, o processo de formação de conceitos "tem como principal traço distinto a passagem de processos imediatos a operações mediadas por leis" (VYGOTSKY, 2000, p. 173). Essas leis estão refletidas nos conceitos na forma de relações e conexões internas do fenômeno, não nos seus aspectos aparentes. Assim descreve Vygotsky (1998, p. 82): “Uma baleia, do ponto de vista de sua aparência externa, situa-se mais próxima dos peixes do que dos mamíferos; mas, quanto à sua natureza biológica está mais próxima de uma vaca ou de um veado do que de uma barracuda ou de um tubarão."

De acordo com Davydov (1988, p. 72), ter um conceito é saber reproduzir mentalmente o conteúdo de um objeto sendo que "a ação mental de sua construção e transformação constitui o ato de sua compreensão e explicação, o descobrimento de sua essência". Para ele, o ensino escolar é o principal e mais privilegiado modo pelo qual os alunos adquirem os conceitos científicos e, com isso, desenvolvem seu pensamento. Por isso defende que o conteúdo da atividade de aprendizagem é o pensamento teórico (pensamento por conceitos), que desempenha o papel de ferramenta mental para a compreensão e análise dos objetos.

Todo conceito científico resulta de processos e procedimentos lógicos de investigação de um objeto em uma área de conhecimento e de pesquisa, envolvendo certos caminhos de pensamento e de análise. É um tipo de pensamento 
que requer ações mentais de abstração, generalização, conceito (pensamento teórico, científico). $\mathrm{Na}$ atividade de aprendizagem, os alunos devem apropriar-se dos conteúdos não apenas como resultado de investigações, eles devem, sobretudo, apropriar-se do processo de pensamento que permitiu o seu surgimento, pois esta forma de aprender proporciona o desenvolvimento de funções mentais que os alunos ainda não tenham formado. Esse deve ser o objetivo do ensino e que sua organização nada mais é que a organização da atividade do próprio aluno, proporcionando-lhe um caminho para obter as conclusões científicas sobre os objetos e os seus conceitos.

O conceito teórico constitui-se como uma base universal para a dedução de aspectos particulares e singulares pelos quais o objeto se apresenta na realidade social, em contextos culturais e históricos. Sendo a essência do objeto, o conceito teórico permite lidar com o movimento dialético entre sua essência e sua aparência, suas conexões internas e externas. Esse consiste no movimento do pensamento do abstrato para o concreto e é também o movimento pelo qual deve ser organizada a atividade dos alunos (DAVYDOV, 1988).

Torna-se importante aqui a distinção que há entre conceito e definição. A definição de um objeto é um conhecimento que permanece preso apenas à sua aparência, à sua superficialidade. A definição, meramente, não possibilita perceber o movimento do objeto nas relações entre totalidade e particularidade. A definição permite apenas a descrição simples do objeto. Por exemplo, a descrição somente de uma fórmula é uma definição. Uma fórmula como síntese de um movimento de sua investigação e reflexão teórica associada a um objeto, como modo de procedimento mental de análise desse objeto, é um conceito. Fica então muito claro que no ensino desenvolvimental a aquisição de conteúdos pelo aluno é valorizada em uma dimensão qualitativa, em seu papel transformador das ações mentais dos alunos. O importante não é o conteúdo em si mesmo, mas o novo modo de pensamento que o aluno forma ao aprendê-lo: o conceito.

Nessa perspectiva, Hedegaard (2002) compreende que o professor precisa se movimentar a partir do conhecimento profundo dos conceitos e de suas leis gerais para direcionar as distintas etapas do ensino. Já os alunos precisam partir da investigação dessas leis gerais e suas manifestações, por meio de atividades práticas de investigação. Concretizar esse movimento requer antes a análise lógica e histórica do conceito. Essa análise visa examinar o objeto em sua origem e desenvolvimento histórico, identificando suas leis gerais, seu aspecto nuclear, essencial. Só então se formulam as ações mentais na forma de tarefas com caráter problematizador, para desafiar intelectualmente os alunos. Davydov (1988) sintetizou em cinco passos as ações para organização do ensino em conexão com as ações dos alunos: 1) transformação dos dados da tarefa e obtenção do núcleo do conceito; 2) modelação da relação conceitual básica identificada; 3) 
transformação do modelo e análise das suas relações; 4) realização de tarefas particulares utilizando o conceito; 5) monitoramento e controle de todas as ações. Esta última etapa corresponde ao exame consciente e deliberado que o aluno faz de sua atividade mental durante as ações, e por isso pode ser considerado também uma autoavaliação. No início, os alunos necessitam de ajuda para executar as ações e, gradativamente, vão atingindo um grau de desenvolvimento que lhes possibilita independência.

\section{Ensino desenvolvimental e formação do conceito de sólidos geométricos}

Davydov estendeu o método investigativo de Vygotsky à pesquisa de cunho pedagógico e didático, como experimento didático formativo, ou experimento formativo de ensino. Este método de pesquisa "plasma a unidade" entre a investigação do desenvolvimento mental das crianças e sua educação e ensino (DAVYDOV, 1988, p. 107). O experimento didático formativo estrutura-se em aulas com o objetivo de ajudar os alunos a avançaram a um estágio ou nível de desenvolvimento em relação ao conceito estudado.

A presente pesquisa caracterizou-se como experimento didático formativo nesta perspectiva. A parte empírica ocorreu no ano de 2010, envolvendo o professor de Matemática e seus 27 alunos de segunda série do Ensino Médio, em uma escola pública estadual localizada em Goiás. A escolha desta série foi pelo fato de ser nela que, durante o Ensino Médio, é ensinado o conteúdo de geometria espacial. A escolha da escola foi pelo baixo desempenho no IDEB (Índice de Desenvolvimento da Educação Básica) divulgado em 2009: 2,6 de média em relação à meta 6,0. Para a escolha da turma, foram considerados os critérios: aceite em participar da pesquisa (professor, alunos e pais); aulas em turno que possibilitasse a coleta de dados por uma das pesquisadoras.

Os dados foram coletados por meio de entrevistas com o professor e os alunos, observação da escola (48 horas) e das aulas de Matemática (52 horas), avaliação da aprendizagem dos alunos em relação ao conteúdo de sólidos geométricos, antes (diagnóstica I) e após o desenvolvimento do plano de ensino (diagnóstica II, formação do conceito). Neste artigo são apresentados somente dados originados das observações.

O plano de ensino foi formulado pelas pesquisadoras e apresentado ao professor de Matemática, que o desenvolveu em 16 aulas de 50 minutos. Coube a ele a concretização de todas as suas etapas o que o tornou, além de sujeito, colaborador da pesquisa. Para isso, foi necessário que estudasse alguns conceitos básicos da teoria de Davydov, com discussão e esclarecimento de dúvidas por uma das pesquisadoras. As observações e entrevistas foram registradas em caderno de campo e gravação em áudio. 
A análise lógico-histórica do conceito de volume de sólidos geométricos (prisma, pirâmide, cilindro e cone) foi realizada como condição para a formulação do plano de ensino. Referindo-se à importância da análise lógico-histórica do conceito pelo professor de Matemática, Moretti (2010) lembra que na base da construção e desenvolvimento histórico dos conceitos encontram-se as necessidades que moveram a humanidade a buscar soluções para os problemas e desafios com que vai se deparando historicamente. É desta forma que o aspecto lógico encontra-se unido ao aspecto histórico do conceito.

Pela análise lógico-histórica, constatou-se que o conceito de volume ou capacidade, geralmente presente nos livros didáticos, corresponde à quantidade de espaço que ele ocupa ou de que dispõe para armazenar. Esta é, na verdade, apenas uma ideia intuitiva do número de vezes que um sólido contém o cubo unitário, a qual direcionou a dedução das fórmulas. Ideia sobre volume seria, por exemplo, a quantidade de areia retirada de um rio, dejetos poluentes despejados em mares, entulho retirado de uma obra. Já a noção de capacidade seria, por exemplo, uma garrafa, uma seringa, uma piscina. Os egípcios e babilônicos mostraram que se pode medir sem a expressão literal do volume, através da sua relação principal de medição. A investigação e estudo de várias gerações de matemáticos permitiu o desenvolvimento histórico dos conceitos, até que os gregos desenvolveram uma geometria mais formal e axiomática, mostrando que o aspecto essencial do volume é a relação da área da base com a altura. Essa análise lógico-histórica resultou na compreensão deste como o conceito geral de volume.

Elucidado o conceito, foi organizado o plano de ensino com o objetivo geral de promoção de mudanças qualitativas nas ações mentais dos alunos, no seu modo de pensar e analisar sólidos geométricos, a partir da apreensão da relação essencial entre a área da base e a altura. Considerando-se o conceito de zona de desenvolvimento proximal, antes que o professor colocasse em prática o plano de ensino, foi realizada uma avaliação diagnóstica, verificando-se o conhecimento que os alunos já apresentavam, e o que ainda não sabiam, acerca de volume. O resultado foi utilizado na estruturação das tarefas. Na última etapa, foi realizada a mesma avaliação, a fim de se verificar indícios de mudanças qualitativas no modo mental de trabalho dos alunos com o conceito de volume.

Seguindo a proposta de Davydov (1988), as tarefas foram apresentadas na forma de problemas a serem resolvidos, ressaltando a experiência sociocultural dos alunos, a interação durante a tarefa, a mediação didática do professor, o movimento de trabalho do coletivo para o individual, o movimento de pensamento do geral para o particular, do abstrato ao concreto, ou seja, da apreensão do conceito à sua concretização em tarefas representativas de situações concretas. As ações mentais propostas, ao levar em conta elementos do cotidiano da 
escola e da vida dos alunos detectados nas observações e entrevistas, possibilitou introduzir suas vivências, visando influenciar seus motivos para aprender e seu envolvimento ativo nas ações. Foram constituídas etapas correspondentes às cinco ações propostas por Davydov. A "identificação da relação geral" e a "modelação" foram desenvolvidas de forma integrada, como se vê na síntese a seguir.

Quadro 1 - Etapas correspondentes às ações de aprendizagem realizadas pelos alunos

\begin{tabular}{|c|c|}
\hline Etapas do ensino & Ações de Aprendizagem dos alunos \\
\hline $\begin{array}{l}1 \text { - Envolvimento dos alunos na } \\
\text { atividade de aprendizagem do } \\
\text { conceito de sólidos geométricos. }\end{array}$ & $\begin{array}{l}\text { Identificar os sólidos geométricos. } \\
\text { Em grupo, encontrar sólidos geométricos no espaço físico } \\
\text { da escola e tentar reproduzi-los utilizando caixas de sapato. }\end{array}$ \\
\hline $\begin{array}{l}2 \text { - Identificação da relação geral } \\
\text { básica: Princípio de Cavalieri, e, } \\
3 \text { - Modelação da relação geral } \\
\text { básica (Princípio de Cavalieri) }\end{array}$ & $\begin{array}{l}\text { Em grupo, investigar e descobrir o Princípio de Cavalieri } \\
\text { utilizando pilhas de livros e material bibliográfico. } \\
\text { Reconhecer nesse princípio a relação geral, nuclear. } \\
\text { Construir o modelo geral de volume. }\end{array}$ \\
\hline $\begin{array}{l}4 \text { - Transformação do modelo } \\
\text { e análise das relações como } \\
\text { consequência das mudanças. }\end{array}$ & $\begin{array}{l}\text { Estabelecer a relação entre os volumes do prisma e da } \\
\text { pirâmide. }\end{array}$ \\
\hline $\begin{array}{l}5 \text { - Resolução de tarefas envolvendo } \\
\text { casos particulares com a utilização } \\
\text { do modelo. }\end{array}$ & $\begin{array}{l}\text { Analisar e relacionar o volume dos sólidos em estudo: } \\
\text { prisma, pirâmide, cilindro e cone. }\end{array}$ \\
\hline $\begin{array}{l}6 \text { - Controle e monitoramento das } \\
\text { ações. }\end{array}$ & $\begin{array}{l}\text { Examinar, durante cada ação, individual e coletivamente, o } \\
\text { caminho da aprendizagem em relação à exigência da tarefa. }\end{array}$ \\
\hline $\begin{array}{l}7 \text { - Avaliação da aprendizagem do } \\
\text { conceito de sólidos geométricos. }\end{array}$ & $\begin{array}{l}\text { Solucionar, individualmente, a tarefa com finalidade de } \\
\text { avaliação, pelo professor, da aprendizagem do conceito de } \\
\text { volume. }\end{array}$ \\
\hline
\end{tabular}

Fonte: As autoras.

\section{Etapa 1 - Identificação dos sólidos geométricos}

Afirma Davydov (1999) que, do mesmo modo que não se pode forçar uma criança a brincar, pois ela deve sentir necessidade de brincar, também não se pode forçar um aluno a entrar em atividade de aprendizagem se ele não sentir necessidade de fazê-lo. Considerando esta premissa teórica, na primeira etapa, as ações tiveram o objetivo de mobilizar os alunos, subjetivamente, a entrarem em relação com o objeto da aprendizagem, a sentirem necessidade de conhecer alguns sólidos geométricos para sua utilização ao resolverem os problemas propostos nas tarefas e ações. 
Quadro 2 - Síntese da Etapa 1

\begin{tabular}{|l|l|}
\hline \multicolumn{1}{|c|}{ Objetivos } & \multicolumn{1}{|c|}{ Ações de Aprendizagem dos alunos } \\
\hline $\begin{array}{l}\text { 1. Aguçar a visualização e percepção } \\
\text { da presença de figuras planas no } \\
\text { espaço da escola. }\end{array}$ & $\begin{array}{l}\text { Em grupo, registrar áreas de figuras planas observadas no } \\
\text { espaço físico e em objetos presentes na escola. } \\
\text { Exposição e discussão coletiva dos achados. }\end{array}$ \\
\hline $\begin{array}{l}\text { 2. Compreender a origem e e } \\
\text { transformação histórica da } \\
\text { geometria espacial. }\end{array}$ & $\begin{array}{l}\text { Em grupo, investigar a origem dos sólidos geométricos, } \\
\text { utilizando material bibliográfico da biblioteca e do } \\
\text { laboratório de informática da escola. } \\
\text { Expor e discutir coletiva dos resultados da pesquisa. }\end{array}$ \\
\hline $\begin{array}{l}\text { 3. Construir, ou tentar construir, } \\
\text { modelos geométricos. }\end{array}$ & $\begin{array}{l}\text { Construir alguns sólidos geométricos com papelão e } \\
\text { "liguinha" de borracha. }\end{array}$ \\
\hline
\end{tabular}

Fonte: As autoras.

Os alunos já possuíam alguns conhecimentos sobre o conteúdo, detectado na avaliação diagnóstica, e estes foram relembrados, com os alunos pesquisando e apresentando conclusões sobre os sólidos geométricos. Após, o professor, questionou-lhes: "Agora, digam-me alguns exemplos, do dia a dia, de sólidos geométricos". Os alunos apresentaram diversas respostas: "a caixa de giźé um cubo"; "o chapeuzinho de aniversário é um cone"; "também o cone que coloca no asfalto para alerta"; "tem também a casquinha de sorvete, que é um cone"; "a pirâmide do Egito"; "o giz, professor, é um cilindro". O professor perguntou: "E a caneta "bic", é um poliedro?" Os alunos responderam: "Não. Porque a ponta não é igual ao resto da caneta". O professor continuou indagando: "E o que é semelhante nestes sólidos que vocês me falaram?" Rapidamente os alunos responderam: "O prisma possui duas bases"; "O cilindro também"; "A pirâmide tem uma pontinha e só uma base"; "O cone também, só que a base é diferente da pirâmide, é um círculo".

Percebe-se que vários alunos começaram a diferenciar figuras bidimensionais de figuras tridimensionais em objetos do cotidiano que são formas particulares de sólidos geométricos. Mas alguns ainda trabalharam mentalmente apenas com os aspectos percebidos imediatamente, ou seja, a aparência dos sólidos geométricos. Isso pode ser percebido na situação descrita a seguir. O professor apresentou aos grupos a tarefa: "Descreva os sólidos geométricos encontrados no espaço físico da escola e registre em um papel". Os alunos observaram o espaço físico da escola e registraram o que foram encontrando. No registro de um dos grupos verificou-se: "lâmpada $\rightarrow$ cilindro; janela $\rightarrow$ quadrado; balde $\rightarrow$ cone; pneus $\rightarrow$ círculo; banco $\rightarrow$ retângulo; lata de lixo $\rightarrow$ cilindro; vaso de plantas $\rightarrow$ cone; bloco de cimento $\rightarrow$ paralelepípedo; bolinha de "ping pong" $\rightarrow$ esfera; encontro das telhas $\rightarrow$ triângulo; tijolo $\rightarrow$ retângulo". Neste registro nota-se que o grupo não conseguiu distinguir figuras bidimensionais de figuras tridimensionais. A ideia das figuras planas persistiu para alguns alunos, sendo o indício dessa persistência o registro do tijolo como um retângulo. 
Percebendo essa ocorrência, a mediação didática do professor consistiu em pedir aos alunos que discutissem os resultados dos registros, levando-os a analisar por que o bloco de cimento foi registrado como paralelepípedo e o tijolo não. Após, apresentou a pergunta: "É possivel construir os sólidos geométricos encontrados com base na observação física da escola, utilizando como materiais papelão e liguinha?" Todos os alunos concordaram que sim. O professor entregou os materiais aos grupos, orientando os grupos quanto ao objetivo e condições da construção.

Como expõe Pohl (1994, p. 178), "a melhor maneira de aprender a visualizar o espaço tridimensional é construindo objetos que mostrem os conceitos espaciais", o que também oportuniza aos alunos a aprendizagem do vocabulário e das relações da Matemática. Por sua vez, Davydov (1999) defende que os experimentos são o único caminho para que os alunos identifiquem as inter-relações entre conteúdo interno e externo de um objeto, de um conceito, pois sempre envolvem a criação por parte dos alunos. Este foi o propósito ao se solicitar aos alunos a construção de sólidos geométricos identificados a partir do material indicado.

Concluída esta ação, os grupos apresentaram e discutiram o sólido e sua respectiva denominação. Após, o professor colocou alguns problemas: "O que distingue os sólidos geométricos durante sua construção? É possível estabelecer relações entre esses sólidos?" O professor solicitou que avaliassem e registrassem as conclusões encontradas sobre sólidos geométricos durante as ações da Etapa 1, como suas semelhanças, diferenças e relações. Algumas das conclusões registradas foram: "O prisma hexagonal tem duas bases, e faces retangulares e a pirâmide tem uma base e faces em forma de triângulo. O cilindro tem duas bases, e o cone tem só uma base, os dois têm a base circular". Nota-se que os alunos captaram as diferenças entre pirâmide e prisma, entre cilindro e cone, entre prisma e pirâmide, identificando a relação entre bases e também perceberam a diferença da quantidade de base entre o cilindro e o cone. Estes foram considerados indícios de que eles entraram em um movimento de pensamento colocando-se em direção ao aspecto essencial do conceito de sólidos geométricos. A constatação permitiu passar à etapa seguinte.

\section{Etapas 2 e 3 - Identificação e modelação da relação geral básica: Princípio de Cavalieri}

Ao interpretar a proposta de Davydov para a organização do ensino desenvolvimental, Freitas (2008, p. 7) escreve: "a forma inicial da ação da aprendizagem é a transformação dos dados objetais da tarefa visando constituir a ação mental”. Nesta etapa, portanto, os alunos foram desafiados intelectualmente a descobrirem a relação geral, principal, básica. 
Quadro 3 - Síntese das Etapas 2 e 3

\begin{tabular}{|l|l|}
\hline \multicolumn{1}{|c|}{ Objetivos do ensino } & \multicolumn{1}{|c|}{ Ações de Aprendizagem } \\
\hline 1. Compreender o Princípio de Cavalieri. & $\begin{array}{l}\text { Comparação entre pilhas de livros, sabendo que } \\
\text { possuem mesma base e a mesma altura. }\end{array}$ \\
\hline $\begin{array}{l}\text { 2. Expressar uma fórmula geral para a a } \\
\text { relação principal do sólido geométrico } \\
\text { prisma paralelepípedo (modelação). }\end{array}$ & $\begin{array}{l}\text { Investigação dos procedimentos para se obter o } \\
\text { volume de uma borracha e a dedução da extração do } \\
\text { princípio geral. }\end{array}$ \\
\hline $\begin{array}{l}\text { 3. Expressar uma fórmula geral para a } \\
\text { relação principal do cubo }\end{array}$ & $\begin{array}{l}\text { Investigação dos procedimentos para se obter o } \\
\text { volume do cubo e a dedução da extração do princípio } \\
\text { geral. }\end{array}$ \\
\hline
\end{tabular}

Fonte: síntese elaborada pelas pesquisadoras

Com o objetivo de estimular os alunos a pensarem sobre a utilização de um procedimento geral de pensamento, o professor apresentou perguntas: "É possível calcular o volume de qualquer prisma? Como chegar ao volume de um prisma"? Colocou três pilhas de 6 livros, em diferentes alinhamentos, indagando à turma: "Qual pilha de livros possui maior volume?” Os alunos responderam: "A terceira". "Não, é a segunda". Então o professor perguntou: "Qual, então?" Os alunos calaram-se e pensaram. Uma aluna respondeu: "É igual". O professor indagou por que e a aluna afirmou: "É porque os livros são todos iguais e possuem a mesma quantidade". "Então qual é a relação entre os volumes?", perguntou o professor. A aluna respondeu: "como têm a mesma quantidade de livros, as alturas são iguais, e as bases também, pois todos os livros são iguais". O professor disse: "muito bem"!

Em seguida ele estimulou os alunos a examinarem o raciocínio da aluna, colocando-os para movimentarem as pilhas de livros. Um aluno retirou um livro e disse: "esse livro é igual ao da base da pilha, mesmo estando desalinhado não muda, é como se fosse um corte que fornece o mesmo tamanho". O professor confirmou que os volumes são os mesmos, independentemente da geometria obtida pela deformação na segunda pilha de livros, uma vez que foram utilizados livros do mesmo formato e quantidades iguais para cada pilha. Informou aos alunos que esses resultados, ligeiramente generalizados, representavam o Princípio de Cavalieri, enunciado como:

- Se duas porções planas são tais que toda reta secante a elas e paralela a uma reta dada determina nas porções segmentos de reta cuja razão é constante, então, a razão entre as áreas dessas porções é a mesma constante. E isso nos leva a dizer que as áreas das duas porções são iguais. 
- Se dois sólidos são tais que todo plano secante a eles e paralelo a um plano dado determina nos sólidos, secções cuja razão é constante, então, a razão entre os volumes desses sólidos é a mesma constante. Em outras palavras: dois sólidos com a mesma altura têm o mesmo volume se seccionados por um plano paralelo ao plano onde estão assentados, geram áreas iguais.

A discussão realizada pelos alunos indicou que estavam desenvolvendo a compreensão necessária à modelação. A modelação, afirma Davydov (1988), envolve a ação criadora dos alunos, como riqueza humana objetivada na manifestação de seus talentos criativos. Este tipo de trabalho mental é essencial à tarefa da escola para o alcance de um de seus objetivos essenciais hoje: formação da personalidade criadora dos alunos, como caráter essencial e distintivo do ser humano.

O professor solicitou-se aos alunos um modelo na forma literal pela tarefa: "A borracha escolar representa um prisma conhecido por paralelepípedo. Tomando como unidade o volume de um cubo unitário de volume 1 , calcule o volume da borracha abaixo e deduza uma fórmula para seu raciocínio".

Figura 1 - Bloco subdividido em 3x2x2 cubos unitários

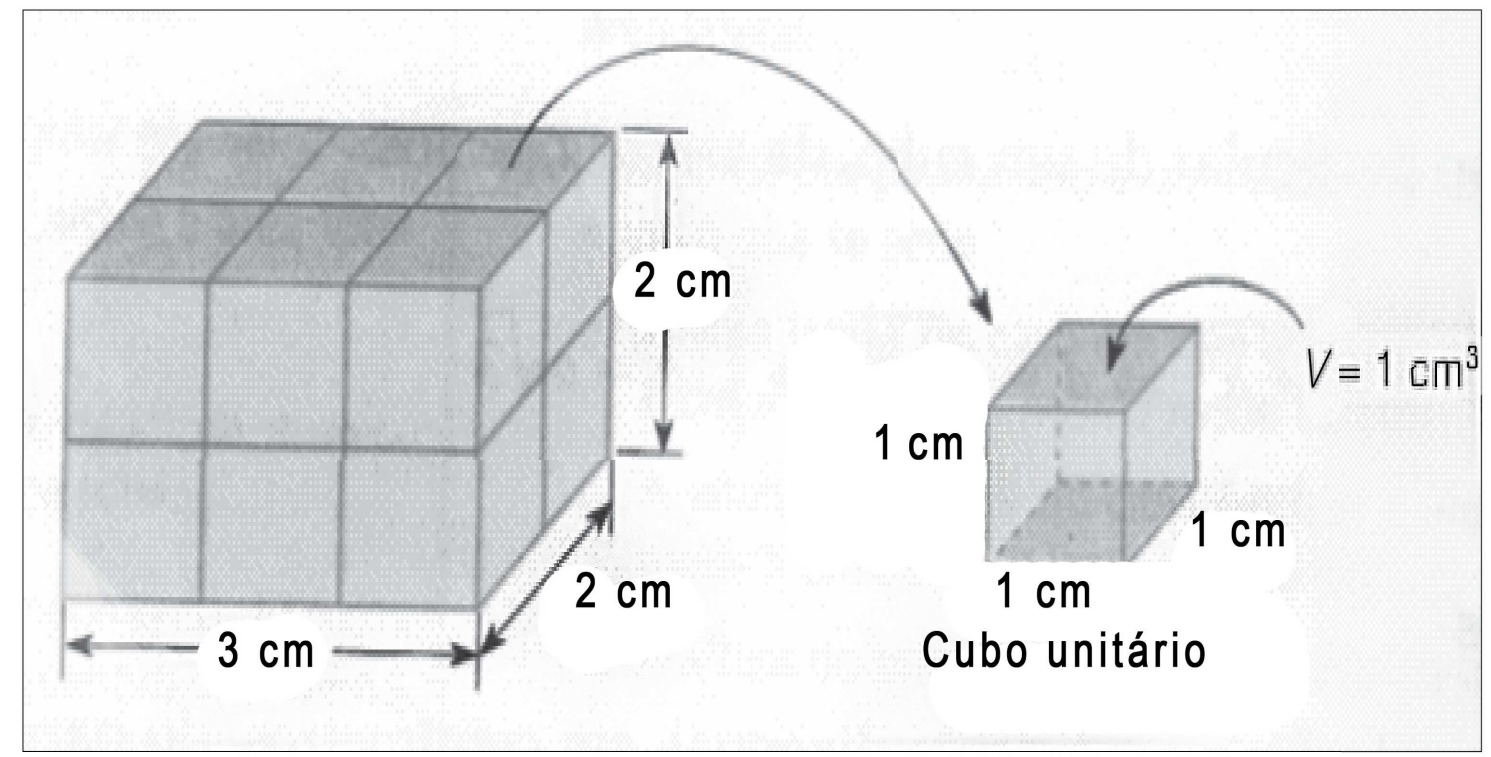

Fonte: Dante (2008), p. 253.

Na sequência, houve o seguinte diálogo:

Prof:: Qual é o volume do paralelepípedo desta tarefa?

Daiane: $\mathrm{O}$ senhor quer saber quantos cubinhos têm nele?

Prof.: É sim.

Alunos: 36, 24, 20. 
Franco: Não, eu acho que é 12.

Prof.: Explique por que 12.

Franco: É só contar! Tem 6 na frente e 6 atrás.

Prof.: Certo. Mas como poderíamos escrever uma fórmula literal para representar esse cálculo?

Mônica: É só multiplicar.

Gustavo: Multiplicar o quê?

Fábia: Multiplicar 3 × 2 × 2 .

Prof.: Que dimensões são essas?

Fábia: É o comprimento, a largura e a altura.

Prof.: Como você escreveria uma fórmula para isso?

Fábia: $V=c \cdot h \cdot l$

Quando o professor questionou sobre a quantidade de cubinhos presentes no paralelepípedo, os alunos tenderam a respostas imediatas, sem recorrerem ao princípio geral. Para torná-los conscientes dessa tendência, o professor chamou a atenção com indagações. O grupo 4 registrou: "Reparti o cubo ao meio e contei seis quadrinhos de cada lado, comprimento x largura x altura. 2 x $2=4$ x $3=12$ ". Os alunos dividiram a figura ao meio, evitando o erro de contar duas vezes os cubinhos. No entanto, em outros grupos os alunos contaram 24, pois um mesmo cubinho era contado duas vezes. Com a mediação do professor, perceberam o distanciamento em relação à ação de aprendizagem proposta e, após correções, deduziram o princípio geral para o volume de um paralelepípedo.

\section{Etapas 4 - Transformação do modelo}

A etapa da transformação do modelo visa fazer com que os alunos analisem as propriedades da relação universal identificada e representada criativamente no modelo. Transformar e reconstruir o modelo permite o estudo das propriedades da relação universal (DAVYDOV, 1988).

Quadro 4 - Síntese da Etapa 4

\begin{tabular}{|c|c|}
\hline Objetivos & Ações de aprendizagem dos alunos \\
\hline $\begin{array}{l}\text { 1. Transformar o modelo para } \\
\text { expressar uma fórmula geral para a } \\
\text { relação do cubo. }\end{array}$ & $\begin{array}{l}\text { Investigação dos procedimentos para obter o volume } \\
\text { do cubo. }\end{array}$ \\
\hline $\begin{array}{l}\text { 2. Identificação da relação entre os } \\
\text { volumes de prismas e de pirâmides. }\end{array}$ & $\begin{array}{l}\text { Utilizando barras de sabão, descrever a transformação } \\
\text { de um prisma em três pirâmides. }\end{array}$ \\
\hline $\begin{array}{l}\text { 3. Concretização da pirâmide } \\
\text { utilizando um artefato matemático, o } \\
\text { geoespaço. }\end{array}$ & $\begin{array}{l}\text { Utilizando "liguinha" de borracha e o geoespaço, } \\
\text { construir diversas pirâmides. }\end{array}$ \\
\hline
\end{tabular}

Fonte: As autoras. 
Partindo da atividade da etapa anterior, visto que os alunos já construíram o modelo para volume de um prisma, o professor mostra o material dourado e continua indagando os alunos.

Prof.: Qual o nome da peça maior?

Alunos: Cubo.

Prof.: Então, qual será o volume dele?

Daiane: É 1000.

Prof.: Como você calculou?

Daiane: Multipliquei 10 três vezes.

Prof:: Qual a diferença do volume do paralelepípedo e do cubo?

Marta: É que os lados do cubo são todos iguais.

Prof.: Então, como ficaria a fórmula de seu volume?

Mônica: $V=a^{3}$

Prof.: Muito bem. Mas e se o prisma fosse de base triangular? Como calcularia o volume dele?

Franco e Pâmela: É só calcular a área do triângulo.

Prof.: E como ficaria a fórmula?

Franco e Pâmela: É a mesma.

Prof.: Como? O produto do comprimento, da largura e da altura?

Franco: É, o comprimento vezes a largura é a área da base, então, o volume é a área da base vezes a altura.

$\mathrm{Na}$ utilização do princípio geral, a mediação didática do professor foi fundamental para que os alunos identificassem e transformassem o modelo do paralelepípedo em cubo, generalizando em seguida para qualquer prisma. O professor entregou aos alunos barras de sabão, e pediu que estabelecessem a relação do espaço que um prisma dispõe para armazenar outro sólido de mesma base e mesma altura. Os alunos realizaram o movimento de transformação de um prisma a uma pirâmide, com os cortes corretos na barra de sabão, reconstruindo a expressão literal do volume de um prisma no da pirâmide $\left(V=\frac{A_{b} \cdot h}{3}\right)$.

Tendo relacionado o volume do prisma com o da pirâmide, o professor encerrou a etapa 4 pedindo os alunos para construírem diversas pirâmides utilizando o geoespaço.

\section{Etapa 5 - Resolução de casos particulares com a utilização do modelo}

Como já descrito, para Davydov (1988), esta ação possibilita aos alunos utilizarem o conceito enquanto um princípio geral (abstrato), como procedimento mental para a análise de problemas ou casos particulares, inseridos em situações e contextos distintos na realidade concreta. 
Quadro 5 - Síntese da Etapa 5

\begin{tabular}{|l|l|}
\hline \multicolumn{1}{|c|}{ Objetivos } & \multicolumn{1}{|c|}{ Ações de Aprendizagem dos alunos } \\
\hline $\begin{array}{l}\text { 1. Analisar a semelhança entre o volume do } \\
\text { prisma e cilindro. }\end{array}$ & $\begin{array}{l}\text { Discutir e explicitar o caminho mental percorrido } \\
\text { para identificar a relação dos volumes do prisma } \\
\text { e cilindro. }\end{array}$ \\
\hline $\begin{array}{l}\text { 2. Analisar a semelhança entre os volumes da } \\
\text { pirâmide e cone. }\end{array}$ & $\begin{array}{l}\text { Discutir e explicitar o caminho mental percorrido } \\
\text { para identificar a relação dos volumes da pirâmide } \\
\text { e cone. }\end{array}$ \\
\hline $\begin{array}{l}\text { 3. Examinar as ações realizadas tendo como } \\
\text { referência o conceito estudado. }\end{array}$ & $\begin{array}{l}\text { Utilizar o "software geometria em movimento", } \\
\text { para a comparação entre os sólidos estudados. }\end{array}$ \\
\hline $\begin{array}{l}\text { 4. Solucionar tarefas individualmente utili- } \\
\text { zando o conceito de volume. }\end{array}$ & $\begin{array}{l}\text { Solucionar problemas referentes a volume de pris- } \\
\text { ma, pirâmide, cilindro e cone. }\end{array}$ \\
\hline
\end{tabular}

Fonte: As autoras.

Nesta etapa, o professor entregou aos alunos a figura de um prisma e de um cilindro no mesmo plano, de mesma altura e área da base. Também entregou a figura de uma pirâmide e um cone. Rapidamente, os alunos recorreram ao Princípio de Cavalieri e, utilizando-o, deduziram os volumes do prisma e do cilindro, da pirâmide e do cone.

O grupo 5 registrou a seguinte conclusão sobre a relação dos volumes do prisma e do cilindro: "Os dois tem duas bases e a mesma altura. Para terem o mesmo volume, os dois têm que ter a mesma área da base. $\mathrm{O}$ volume do cilindro é calculado: $V=A_{b} \cdot h \rightarrow V=\pi r^{2}$ ".

Sobre a relação entre os volumes da pirâmide e cone, o grupo 1 fez o seguinte registro: "Volume do cone é $V=\frac{A_{b} \cdot h}{3}$, o volume do cilindro é $V=A_{b} \cdot h$, porque é a mesma relação da pirâmide com o prisma, um cilindro forma 3 cones".

Após, o professor apresentou os sólidos estudados utilizando o software "geometria em movimento", com figuras tridimensionais em movimento. Solicitou à turma a análise dos conceitos presentes no software, visto que neste momento foram reapresentados todos os sólidos estudados anteriormente. Depois, o professor entregou algumas tarefas individuais, observando o princípio do movimento das atividades dos alunos do coletivo para o individual. As tarefas envolveram três situações cotidianas: 1) volume de tinta ocupado por duas latas diferentes, uma no formato de prisma quadrangular e outra de 
cilindro; 2) quantidade de parafina para fazer uma vela aromatizada no formato de uma pirâmide de base quadrada apresentada na questão; 3) dimensões de um copo cônico e o volume de duas bolas de sorvete, questionando se o mesmo transbordaria. O professor acompanhou individualmente a resolução dos problemas, observando e avaliando o uso do conceito pelos alunos como princípio geral.

\section{Etapa 6 - Controle e monitoramento das ações}

Esta ação, que na verdade está presente em todas as demais, visa que o aluno realize acompanhe as próprias ações, averiguando sua qualidade. Como descreve Davydov (1988), consiste no exame consciente e reflexivo da própria capacidade. Pode-se deduzir que se trata de um processo de autoavaliação contínua em que o aluno pode identificar as conexões e relações que está sendo capaz de estabelecer, ainda durante o processo, e não somente ao final, o que the permite reorganizar-se, reposicionar seu caminho, buscando alcançar a aprendizagem.

A sexta etapa, portanto, esteve contida em todas as outras. Por meio dela, os alunos eram impelidos a examinarem seu movimento de pensamento em relação às exigências das tarefas e ao conceito de volume, sua utilização, a ocorrência de mudanças qualitativas em sua compreensão dos sólidos geométricos em estudo, verificando se estavam conseguindo utilizá-lo como uma "ferramenta" na solução dos problemas apresentados em forma de tarefas.

\section{Etapa 7 - A aprendizagem do conceito de volume}

Dando prosseguimento ao movimento das ações do aluno do coletivo para o individual, nesta etapa, o professor pediu a cada aluno que elaborasse e resolvesse uma situação problema envolvendo geometria espacial com a aplicação sistemática do conceito. Esta tarefa serviu ao objetivo do professor de avaliar e verificar em cada aluno a apreensão do conceito.

A aluna Fabiana elaborou o seguinte problema: "Descubra qual das figuras tem maior volume, sendo que o cone tem $20 \mathrm{~cm}$ de altura e diâmetro $10 \mathrm{~cm}$ e o paralelepípedo tem $15 \mathrm{~cm}$ de altura e a área da base 16". Na resolução a aluna apresentou: 

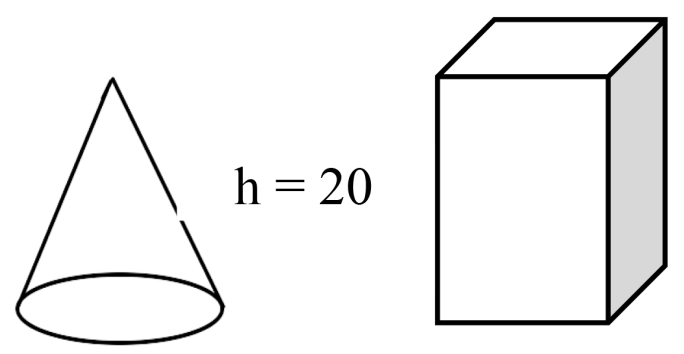

$$
\mathrm{h}=15
$$

$\mathrm{r}=5$

4

$A_{b}=\pi \cdot r^{2}$

$A_{b}=3,14 \cdot 5^{2}$

$A_{b}=3,14 \cdot 25$

$A_{b}=78,5 \mathrm{~cm}^{2}$

$V=\frac{A_{b} \cdot h}{3}$

$V=\frac{78,5 \cdot 20}{3}$

$V=\frac{1570}{3}$

$V=52,33 \mathrm{~cm}^{3}$

O paralelepípedo tem maior volume.

$\mathrm{Na}$ avaliação diagnóstica I, realizada antes do ensino experimental, a turma não conseguiu resolver os problemas envolvendo o conceito de volume dos sólidos geométricos, havendo dificuldades e erros na resolução. A mesma avaliação foi realizada na última ação do ensino desenvolvimental para verificação de mudanças. Descreve-se abaixo a resolução, pela aluna Mônica (nome fictício), de um dos problemas apresentados na tarefa. Essa descrição ilustra a formação do conceito e sua utilização. $\mathrm{Na}$ avaliação diagnóstica I a aluna não resolveu o problema, deixando-o sem resposta. Na avaliação diagnóstica II resolveu-o corretamente, podendo-se perceber que utilizou o conceito.

\section{Tarefa:}

Uma artesã confecciona dois diferentes tipos de vela ornamental a partir de moldes feitos com cartões de papel retangulares de $20 \mathrm{~cm}$ x $10 \mathrm{~cm}$ (conforme 
ilustram as figuras abaixo). Unindo dois lados opostos do cartão, de duas maneiras, a artesã forma cilindros e, em seguida, os preenche completamente com parafina.
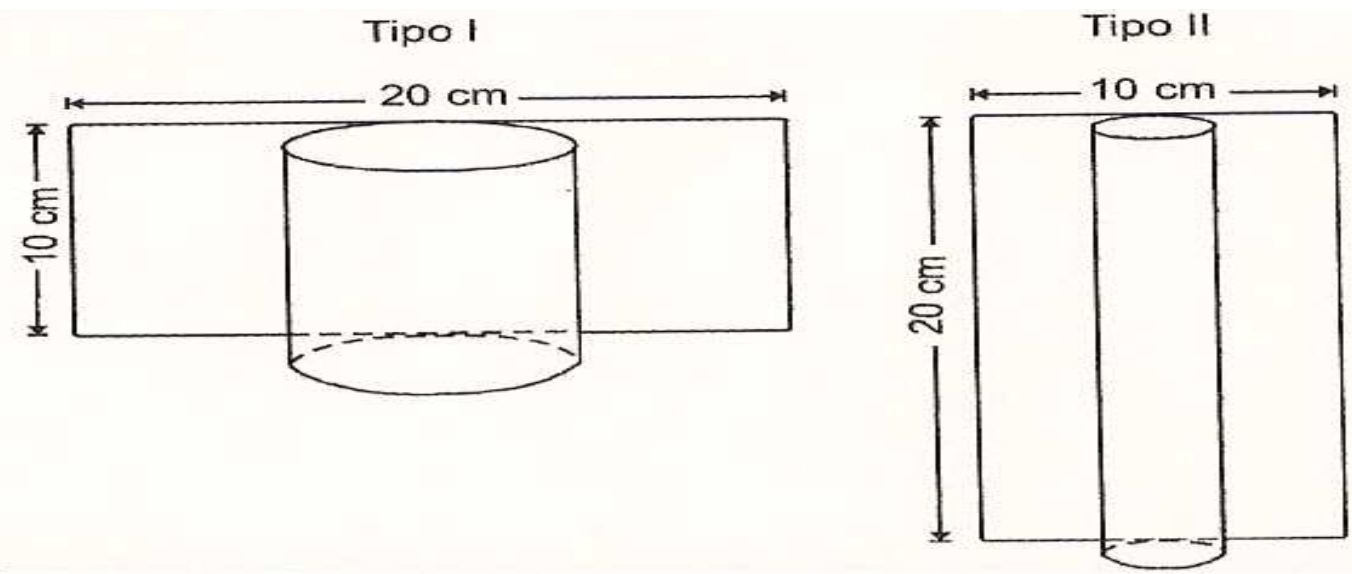

Supondo-se que o custo da vela seja diretamente proporcional ao volume de parafina empregado, qual a vela que possui maior custo, a do tipo I ou a do tipo II?

Solução pela aluna:

\begin{tabular}{lc|cc} 
TIPO I & TIPO II & TIPO I & TIPO II \\
$C=2 \pi r$ & $C=2 \pi r$ & $V=\pi r^{2} . h$ & $V=\pi r^{2} \cdot h$ \\
$20=2.3,14 . r$ & $10=2.3,14 \cdot r$ & $V=3,14 \cdot(3,18)^{2} \cdot 10$ & $V=3,14 \cdot(1,50)^{2} \cdot 20$ \\
$20=6,28 r$ & $10=6,28 r$ & $V=317,52 \mathrm{~cm}^{3}$ & $V=158,76 \mathrm{~cm}^{3}$ \\
$6,28 r=20$ & $6,29 r=10$ & & \\
$r=\frac{20}{6,28}$ & $r=\frac{10}{6,28}$ & \\
$r=3,18 \mathrm{~cm}$ & $r=1,59 \mathrm{~cm}$ &
\end{tabular}

Resposta da aluna: A que possui maior custo é o tipo I.

O exemplo ilustra o caso da aluna e de 18 dos 27 alunos da turma que ao final da execução do plano de ensino passaram a ter o conceito como procedimento de análise do volume de sólidos geométricos. Como ocorre em qualquer abordagem de ensino, também no ensino desenvolvimental nem todos os alunos formaram o conceito. Todavia, a diferença entre a avaliação diagnóstica inicial e a avaliação final, utilizando-se a mesma tarefa foi grande. Antes, aproximadamente $33 \%$ da turma apresentava desempenho superior à média 6 , considerando-se o 
valor de zero a dez para o conjunto da tarefa. Após, na mesma tarefa, aproximadamente $63 \%$ dos alunos atingiram desempenho superior à média 6 , considerando-se o mesmo valor.

Dos nove alunos que não formaram o conceito, um apresentava grande déficit escolar, com ausência de muitos conceitos básicos de Matemática. Os outros oito faltaram à maior parte das aulas não podendo por isso realizar todas as ações no momento da aula. Estes alunos, mesmo tendo realizado posteriormente as ações, não tiveram as mesmas oportunidades de interação no grupo e de mediações do professor. Relataram como motivo para tantas faltas residirem longe da escola e não terem alguém que os incentivasse a ir à escola, a aprender. Entre estes, uma referiu que apesar de seu baixo desempenho em Matemática esta é a disciplina de que mais gosta. Pode-se supor que, caso houvesse continuidade da proposta, estes alunos pudessem também formar o conceito.

Embora não possam ser todos descritos no espaço deste artigo, alguns desafios que se apresentaram e merecem ser aqui destacados, podem ser atribuídos ao contexto da escola, como dificuldades e falhas no processo da escolarização e da gestão da escola, outros dizem respeito ao contexto social e cultural dos alunos, sua atividade principal e suas condições materiais de vida.

a) Não aquisição de conceitos (algébricos, figuras bidimensionais tridimensionais) básicos à compreensão do conceito de volumes de sólidos geométricos, obrigando o professor a retroceder constantemente e implicando em maior tempo para a concretização das ações.

b) Falhas no conhecimento da língua materna, implicando em dificuldade na leitura e interpretação das tarefas, representando obstáculo às ações, por exemplo, elaboração de textos com escrita clara e lógica para explicar e argumentar sobre os procedimentos mentais.

c) Atividade principal dos alunos já não se constituindo no estudo e aprendizagem, e sim, por necessidade de sobrevivência, em diversas formas de trabalho remunerado, criando uma desconexão com o motivo para aprender.

d) Ocorrência de muitas interrupções das aulas por parte de integrantes da equipe gestora, para avisos, comunicados, organização de atividades festivas, venda de ingressos etc., prejudicando o trabalho do professor e da turma.

e) Concessão de muitas bonificacõoes aos alunos na forma de pontos a serem acrescidos na média da disciplina, como incentivo para participação em olimpíadas, em festa junina etc. Considera-se tal prática pode resultar em uma falsa média, não refletindo o real desempenho dos alunos e, o mais importante, não influenciam positivamente em seu motivo para a aprendizagem, reforçando a compreensão de que o mais importante é a pontuação. 
Acredita-se que no contexto de outras escolas públicas esses e outros fatores também possam estar presentes, desfavorecendo as atividades de ensino e de aprendizagem. Sua presença representou desafios, mas não impedimento para o ensino desenvolvimental.

\section{Considerações finais}

Com o objetivo de identificar as contribuições e os desafios do ensino desenvolvimental de geometria espacial, realizou-se o experimento didático formativo no contexto de uma escola pública estadual, para ensino do conceito de volume de sólidos geométricos. A pesquisa realizada, dada a sua natureza, não visou à generalização de resultados, no entanto, os dados permite argumentar favoravelmente à utilização dessa abordagem para a superação de formas de ensinar Matemática que não privilegiam o desenvolvimento do pensamento do aluno associado à formação de conceitos científicos. Todavia, trata-se de uma abordagem muito exigente, que requer do professor domínio apurado do conteúdo específico, consistente formação pedagógica e didática e uma compreensão básica das teorias de Vygotsky e de Davydov.

Alguns fatores que representaram dificuldades, decorrentes do contexto cultural e histórico dos alunos e também aqueles ligados ao processo de escolarização, são representativos do contexto concreto e contraditório em que atua o professor na escola pública brasileira. $O$ ensino desenvolvimental também está sujeito a estas contradições uma vez que, na abordagem histórico-cultural, é na realidade concreta que o pesquisador se move, sendo ela parte do desafio de pesquisar e buscar novos conhecimentos e reflexões sobre o fenômeno. $\mathrm{O}$ experimento didático formativo se realiza é no contexto real da escola, com sua forma de organização, com suas rotinas, envolvendo professores e alunos na vida escolar concreta.

Pode-se considerar como uma contribuição importante desta pesquisa ter mostrado a possibilidade de realizar, neste contexto concreto, o ensino com finalidade principal de mudanças subjetivas nos alunos, em sua atividade mental e prática com o objeto de conhecimento, num contexto de dificuldades e contradições. Essas mudanças são essenciais para a redução das desigualdades educativas, para mais justiça social por parte da escola, buscando promover a aprendizagem como um caminho importante, ainda que não o único, de desenvolvimento da consciência social do aluno, como condição básica da vida em sociedade. 


\section{Referências}

ALMOULOUD, S. A.; MELLO, E. G. S. Iniciação à demonstração aprendendo conceitos geométricos. In: REUNIÃO ANUAL DA ANPED, 23., 2000, Caxambu. Anais... Caxambu, 2000 .

CEDRO, W. L. O espaço de aprendizagem e a atividade de ensino: o clube de Matemática. 2004. 158 f. Dissertação (Mestrado em Educação) - Universidade de São Paulo, São Paulo, 2004.

O motivo e a atividade de aprendizagem do professor de Matemática: uma perspectiva histórico-cultural. 2008. 100 f. Tese (Doutorado em Educação) - Universidade de São Paulo, São Paulo, 2008.

CEDRO, W. L.; MOURA, M. O. Uma perspectiva histórico-cultural para o ensino de álgebra: o clube de Matemática como espaço de aprendizagem. Zetetiké, Campinas, São Paulo, v. 15, n. 27, p. 37-55, jan./jun. 2007.

DANTE, L. R. Matemática: contexto e aplicações. 4. ed. São Paulo: Editora Ática, 2008. (Ensino Médio, 2).

DAVYDOV, V. V. La enseñanza escolar y el desarrollo psíquico. Moscou: Progresso, 1988.

What is real learning activity? In: HEDEGAARD, M.; LOMPSCHER, J. (Eds.). Learning activity and development. Aarhus: University Press, 1999. p. 123-136.

DUVAL, R. Approche cognitive des problemes de geometrie. Annales de Didactiques et de sciences cognitives. IREM de Strarsbourg, 1988. v. 1.

FAINGUELERNT, E. K. Educação Matemática: representação e construção em geometria. Porto Alegre: Artes Médicas Sul, 1999.

FIORENTINI, D. et al. Formação de professores que ensinam Matemática: um balanço de 25 anos da pesquisa brasileira. Educação em Revista - Dossiê Educação Matemática, Belo Horizonte, n. 36, p. 173-160, 2002.

FIORENTINI, D. A formação matemática e didático-pedagógica nas disciplinas da licenciatura em Matemática. Revista de Educação, Campinas, n. 18, p. 107-115, jun. 2005.

A pesquisa e as práticas de formação de professores de Matemática em face das políticas públicas no Brasil. Bolema, Rio Claro, v. 21, n. 29, p. 43-70, 2008.

FREITAS, R. A. M. M. Teoria histórico-cultural e didática: as contribuições de Galperin e Davydov. In: ENCONTRO DE PESQUISA E PÓS-GRADUAÇÃO AS REGIÃO CENTRO-OESTE, 9., 2008, Brasília. Anais... Brasília, 2008.

HEDEGAARD, M. A zona de desenvolvimento proximal como base para o ensino. In: DANIELS, H. (Org.). Uma introdução a Vygotsky. São Paulo: Loyola, 2002. p. 199-227.

LIBÂNEO, J. C. A didática e a aprendizagem do pensar e do aprender: a teoria históricocultural da atividade e a contribuição de Vasili Davydov. Revista Brasileira de Educação, Rio de Janeiro, n. 27, p. 5-24, set./dez. 2004. DOI: 10.1590/S1413-24782004000300002

LIBÂNEO, J. C.; FREITAS, R. A. M. M. Vygotsky, Leontiev, Davidov - contribuições da teoria histórico-cultural para a didática. In: SILVA, C. C.; SUANNO, M. V. R. (Orgs.). 
Didática e interfaces. Rio de Janeiro-Goiânia: Deescubra, 2007. p. 39-60.

LOMPSCHER, J. Learning activity and its formation: ascending from the abstract to the concret. In: HEDEGAARD, M.; LOMPSCHER, J. (Eds.). Learning activity and development. Aarhus (Dinamarca): Aarhus University Press, 1999. p. 139-166.

LORENZATO, S. Porque não ensinar Geometria? Educação Matemática em Revista SBEM, Florianópolis, v. 4, p. 3-13, 1995.

MANRIQUE, A. L. Processo de formação de professores em geometria: mudanças em concepções e práticas. 2003. 169 f. Tese (Doutorado em Educação) - Pontifícia Universidade Católica de São Paulo, São Paulo, 2003.

MORETTI, V. D. O problema lógico-histórico na formação de professores de Matemática em atividade de ensino. In: CONGRESSO INTERNACIONAL PBL, 2010, São Paulo. Anais... São Paulo: USP, 2010.

MORETTI, V. D; MOURA, M. Professores de Matemática em atividade de ensino: contribuições da perspectiva histórico-cultural para a formação docente. Ciência \& Educação, Bauru, v. 17, n. 2, p. 435-450, 2011. DOI: 10.1590/S1516-73132011000200012

MULLER, J. P. La démonstration en géométrie en quatriéme et en troisiéme. Repères IREM, Topiques Edition, n. 15, p. 7-24, avril, 1994.

PAVANELLO, R. M. O abandono do ensino da geometria no Brasil: causas e consequências. Zetetiké, Campinas, v. 1, n. 1, p. 7-18, mar. 1993.

PARSYSZ, B. Articulation entre perception et deduction daans une demarche géométrique en PE1. Extrait du colloque de la COPIRELEM - Tours, 2001.

PEREIRA, M. R. O. A geometria escolar: uma análise dos estudos sobre o abandono de seu estudo. 2001. 84 f. Dissertação (Mestrado em Educação Matemática) - Pontifícia Universidade Católica de São Paulo, São Paulo, 2001.

POHL, V. Visualizando o espaço tridimensional pela construção de poliedros. In: LINDQUIST, M. M.; SHULTE, A. P. (Orgs.). Aprendendo e ensinando geometria. São Paulo: Atual, 1994. p. 178-190.

ROSA, V. M. G. O ensino desenvolvimental e a aprendizagem da equação do $2^{\circ}$ grau. 2009. 124 f. Dissertação (Mestrado em Educação) - Universidade Católica de Goiás, Goiânia, 2009.

SOARES, F. C. C. O ensino desenvolvimental e a aprendizagem de Matemática na primeira fase do Ensino Fundamental. 2007. 118 f. Dissertação (Mestrado em Educação) - Universidade Católica de Goiás, Goiânia, 2007.

VAN HIELE, P. Structure and insight: a theory of mathematics education. Orlando: Academic Press, 1986.

VASCONCELLOS, M. A diferenciação entre figuras geométricas não planas e planas: o conhecimento dos alunos das séries iniciais do Ensino Fundamental e o ponto de vista dos professores. Zetetiké, Campinas, v. 16, n. 30, p. 77-106, jul./dez. 2008.

VYGOTSKI, L. S. Aprendizagem e desenvolvimento intelectual na idade escolar. In: VIGOTSKI, L. S.; LURIA, A. R.; LEONTIEV, A. N. Linguagem, desenvolvimento e aprendizagem. 4. ed. São Paulo: Ícone, 1992. p. 103-117. 
Pensamento e Linguagem. 2. ed. São Paulo: Martins Fontes, 1998.

A construção do pensamento e da linguagem. São Paulo: Martins Fontes, 2000.

A formação social da mente: o desenvolvimento dos processos psicológicos superiores. 7. ed. São Paulo: Martins Fontes, 2007.

Recebido em 23/03/2012

Versão final recebida em 10/03/2013

Aceito em 20/03/2013 